\title{
Analyzation and Optimization of the Omni-Channel Strategy of the Fashion Label 'Marc O'Polo'
}

\author{
Alexander Kluth ${ }^{1}$, Yung-Shen Yen ${ }^{2, *}$ \\ ${ }^{1}$ Department of Business Administration, University of Regensburg, Germany \\ ${ }^{2}$ Department of Computer Science and Information Management, Providence University, Taiwan
}

Copyright $\odot 2019$ by authors, all rights reserved. Authors agree that this article remains permanently open access under the terms of the Creative Commons Attribution License 4.0 International License

\begin{abstract}
This study aims to identify the potential factors for improvement and to generate optimization measures for the Omni-channel strategy. We used the fashion label 'Marc O'Polo', a premium brand in the world, as a study case. This study found that the Omni-channel strategy of Marc O'Polo is compared with the competition with other fashion retailers well-developed, but there are some approaches which miss its target. Thus, we may suggest three points of the Omni-channel strategy for Marc O'Polo, which include that, firstly, triggered or location-based communication by using mobile apps as information and communication tools; Secondly, consistent and centralized social media presentation; Thirdly, personalized online marketing based on customer-generated data.
\end{abstract}

Keywords Omni-Channel, Optimization, Marc O’Polo, Social Media, Location-based Communication

\section{Introduction}

As online retailing has grown rapidly worldwide and become globally competitive, how to retain existing customers to make repeated purchases has become a critical issue for online and offline retailers than ever before. Institutional structure is consistently found to directly promote initial trusting belief and customer satisfaction in an online retailer (Fang et al., 2014). That is the reason why a stable Omni-channel structure derived from the Omni-channel strategy is indispensable to ensure a strong market position. For a better understanding of this content, this study used the fashion label 'Marc O'Polo' as a study case to identify the potential factors for improvement and to generate optimization measures for the Omni-channel structure of 'Marc O'Polo'. In the present study, the methodology of primary analysis of the current situation in combination with existing
Omni-channel concepts and digital devices and services are applied. Moreover, secondary data sources, such as textbooks, journal papers and internet documents are included to underline the contents theoretically.

The next section includes the introduction of 'Marc O'Polo' and the analyzation of the strategy to detect weaknesses. Subsequently approaches for optimizing the Omni-channel strategy of 'Marc O'Polo' are provided. In the end the possible risks and advantages get named while the paper finishes with a conclusion.

\section{About Marc O'Polo}

Marc O'Polo is a premium fashion brand that was founded in Stockholm, Sweden in 1967. In 1997, the company's original distribution partner for Germany, Werner Böck, expanded his shareholdings and formed Marc O'Polo International $\mathrm{GmbH}$, which is today responsible for all company operations from design and production to distribution and marketing. Today, the headquarter is in Stephanskirchen, Germany (Marc O'Polo Einzelhandels GmbH, 2018b). The brand is the embodiment of modern casual wear and the core of its brand identity is a clear preference for natural materials. The assortment of Marc O'Polo comprises premium causal wear and accessories for men and women and ranges from clothing to shoes, eyewear, bags and bed linen (Bloomberg, 2018).

The products of Marc O'Polo are distributed internationally through round about 2,785 stores and retail partners. As of May 2018, Marc O’Polo is available in 96 own stores, 164 franchise stores, at 1,871 retail partners. In total, the brand is represented in approximately 30 countries worldwide (Marc O'Polo Einzelhandels GmbH, 2018a). Marc O'Polo distributes its products through its own online shops and its own mobile app in Germany, Austria, Belgium, France, Switzerland, Sweden and the Netherlands. World-wide, the company employs nearly 2,000 employees (Jobstmann, 2015). 


\section{Omni-Channel Strategy of Marc O'Polo}

Based on the longtime competence in brick and mortar retailing, Marc O’Polo launched its online store in 2003. At the beginning of the collateral channels, both were operated and managed separately (Böttcher, 2015). An essential channel of the Omni-channel strategy of Marc O’Polo is still the offline business. Despite the progressing digitalization, Marc O'Polo pushes the store expansion with a lot of new physical store openings.

As mentioned, the online shop is also an important part of the Omni-channel strategy of Marc O’Polo. The company has invested a single digit million amount in the development of the online business and the closer linkage with the offline stores. As a result of the investment, Marc O’Polo improved the navigation in the online store, shorter loading times due to a responsive web design that enables purchases from all devices. The linkage of online and offline inventories sets the basis for cross-channel activities. With the implementation of RFID technology, the products are now always "online”, can be tracked online and offline and can be traded across all channels. That means that salespersons have the possibility to use the RFID-chips to check the inventory of articles in other stores or online. Thereby it is feasible to order article immediately from everywhere, if a certain article, demanded by a customer, is out of stock (Böttcher, 2015).

To generate synergies between the different channels, the online shop act like an incentive to lead customers to the stores. On the other site, brick and mortar stores guide customers to the online shop. In general, that means that customers can make demands on Omni-channel services, such as Click and Collect, Reserve and Collect and In-Store Order Service (Lettow, 2015).

Moreover, the Omni-channel strategy includes a mobile application. The app provides the whole online shop, offers a store finder as well as information about exclusive specials for members. Besides it gives their users an overview about the purchase processes that are still in progress. In order to complement these channels, Marc O'Polo informs customers by the means of its newsletter about current offers, news and inspirations and promotes campaigns that are implemented online or in-store (Marc O’Polo Einzelhandels GmbH, 2018c). Marc O’Polo is also present on the most important social media platforms, Facebook, Instagram, YouTube, Pinterest, Twitter and Tumblr. The company uses these platforms predominantly to promote outfits and products as well as promotional campaigns.

The relaunch and the international rollout of the online shop in 2014, as well as with the introduction of the new CRM and loyalty program for Members in 2015, in combination with the RFID Technology, Marc O'Polo focuses on an Omni-channel strategy in order to come closer to the goal of offering its customers a consistent and seamless brand experience across all channels. Several channels and services are part of this Omni-channel strategy and are applied in order to meet the individual needs of each customer (Lettow, 2015).

\section{Analyzation of the Current Omni-Channel Strategy}

The Omni-channel strategy of Marc O’Polo is compared with the competition with other fashion retailers well-developed. Nevertheless, there are some approaches which miss their target. Thus, through the analyzation of current Omni-channel strategy, we reveal existing weaknesses.

In general, the missing customization of various the Omni-channel channels pose the main problem in the development of the Omni-channel strategy. For example, a missing customization related to the advertisement and marketing of Marc O'Polo causes a high loss of potential sales. Even though Marc O’Polo generates a huge amount of data from its customers through the various online and offline channels, the direct customer approach is too generalized. The data of every customer offers a new opportunity to individualize the way of contacting the customers by using the preferences, buying behaviors and locations of the customers.

Apart from that, Marc O’Polo is not completely digitalized yet and has unexploited potential concerning the usage and functions of its mobile app and the use of smartphones as a kind of communication tool between company and customers. It is likely that mobile technology and mobile shopping will advance further in the next years. That is the reason why Marc O'Polo should rethink its strategy concerning its mobile app as well as the application of smartphones as communication tool.

The Marc O'Polo social media strategy could be developed much further. Marc O’Polo has no consistent strategy concerning its social media profiles. The inconsistent strategy on Facebook could be another problem area concerning the social media strategy of Marc O’Polo. In addition to its general Facebook page, the company owns several other webpages, promoting the different Marc O’Polo stores. While all these pages show very varying content, they are all disregarding the customer engagement and activity and gain only a small amount of Facebook fans. It seems that these pages are missing a homogenous strategy, cannibalize each other and don't contribute to achieve Omni-channel customer loyalty.

The industry's revolution from Multi-channel to Omni-channel retailing has also a big influence on Marc O’Polo. Due to its structure, the existing Omni-channel strategy is not able to deliver the customer clear insights in the brand experience. Marc O'Polo needs to address its customers in a more targeted way and with the right message at the right time on the right channel (Anderson, 2014; Weber \& Rossi, 2015). 


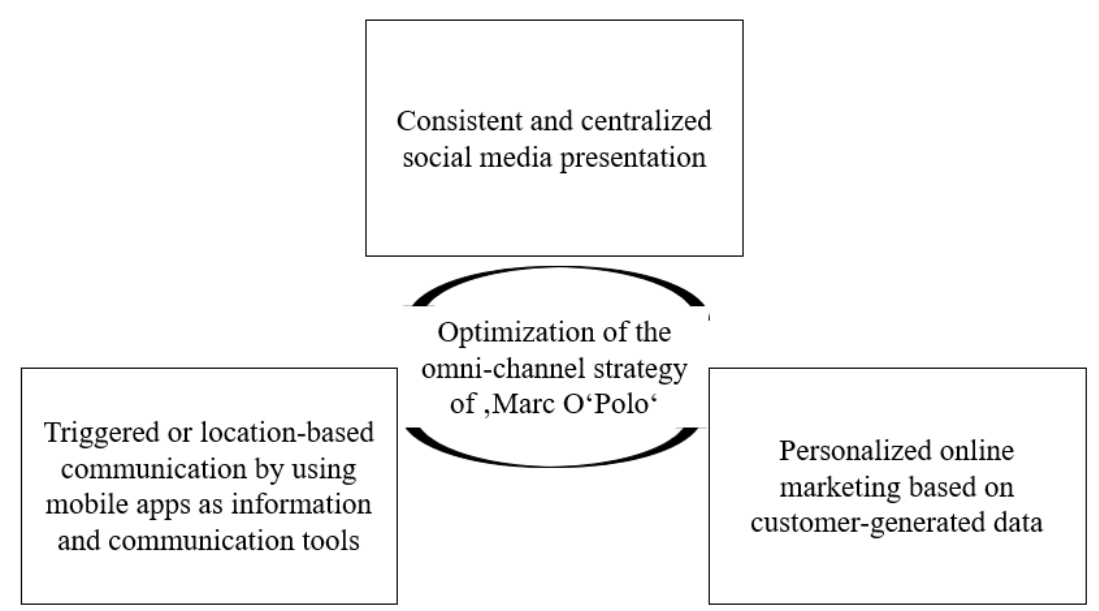

Figure 1. Approaches of optimization

\section{Optimization the Omni-Channel Strategy}

We suggested several approaches to work against the analyzed weaknesses. Figure 1 shows a short overview of the approaches which are explained in detail afterwards.

Marc O'Polo is not tapping the full potential, as customers' use of the app would bare further advantages. Smartphones and mobile apps can serve as information and communication tools within Omni-channel structure, by applying for instance, triggered or location-based communication (Smith, 2015). These ways of communication have great potential because it is possible to reach customers in their everyday-situations, "on the go" and with truly relevant content. That is the reason why real-time and location-based communication should be being part of Marc O’Polos Omni-channel strategy. These include an improvement of the mobile apps related to the extent of functions to seduce the customer into disclosing more information. The mobile apps should provide more functions and services which are able to generate real-time and location-based data.

The social media presentation of the brand should be consistent. This means that all social media activities should be managed centralized. In this case, it could be useful to create an own task field which is responsible for the social media performance. Marc O'Polo can also use the common social media platforms to reward real engagement or to combine the online and offline activities of customers. For example, being implemented by promoting coupons for customers who check in in-store via Facebook, post a picture of their favorite outfit on Instagram and purchase for a certain value in-store (Smith, 2015). The focus on these platforms is on inspiring customers with outfit posts. Customers should be influenced by the products during their daily life while using the social media platforms.

Besides, Marc O'Polo can optimize its E-mail marketing strategy. Customers would like to be addressed with customized offers and a more relevant and personalized communication. For this purpose, Marc O'Polo can use the customer data which it generates in its stores, in its web shop and on the social media platforms. An advice for Marc O'Polo would be to think about how to design its monthly newsletter in a more targeted manner in order to achieve Omni-channel customer loyalty.

For the implementation of the optimizing approaches, the SO-LO-MO concept, short for social media, location-based mobile services and mobile commerce, would be suitable. It serves as framework to integrate new structures and technologies. The concept offers a complete Cross-channel integration and manages offline, online as well as mobile channels. Apart from that, it includes the integration of social media, consumer reviews, personalization of the physical shopping act and use of technological progress in the store as well as the merge of social and local commerce activities (Yumurtacı Hüseyinoğlu et al., 2017).

\section{Conclusions}

To sum it up, it can be concluded that in different aspects Marc O'Polo managed to generate an integrated and consistent brand and shopping experience across all channels. Apart from that, Marc O'Polo connects successfully its strong competence in brick and mortar fashion retailing with the chances of online and mobile commerce. By offering its customers good-working Omni-channel services, such as Click and Collect or Reserve and Collect, the company generates synergy effects for all its channels. However, there are also some aspects concerning the strategy of Marc O'Polo that could be developed much further. Especially the missing customization over the various channels and the unexploited potential of social media marketing and commerce should be considered. The analysis shows that the usage of customer-generated data can help to apply the 
provided approaches. A high volume of customer data would increase the accuracy and efficiency of the necessary measures. The present paper offers several recommendations of action to implement the provided approaches. With a view to the future, Marc O'Polo should work permanently on its Omni-channel strategy to adapt it to the dynamic development of Omni-channel retailing and to achieve an advanced level of Omni-channel loyalty.

Therefore, the contribution of the study includes that, theoretically, we extended the Omni-channel strategy in the context of apparel and accessories stores. Practically, we adopted the SO-LO-MO concept, including social media, location-based mobile services and mobile commerce, to implement the Omni-channel strategy for Marc O’Polo.

However, this study may contain several limitations. First, this study conducted a thought-out case study to explore the Omni-channel strategy of Marc O'Polo in Germany. The improvement points we proposed need further interview with the managers of Marc O'Polo, or examine that through an empirical research. Second, the Omni-channel services can provide a seamless shopping experience for consumers. However, integrating all channels and customer data as one system is more complex and unpredictable (Coughlan et al., 2001). Thus, the support of information technology is a critical issue for implementing the Omni-channel strategy.

\section{REFERENCES}

[1] Anderson, D. (2014). The Importance of Loyalty Programs to Retail Omnichannel. builtinchicago.org. Available online at https://www.builtinchicago.org/blog/importance-loyaltyprograms-retail-omnichannel, updated on 2/17/2014, checked on 1/19/2019.

[2] Bloomberg (2018). Company Overview of Marc O'polo International Gmbh. Textiles, Apparel and Luxury Goods, https://www.bloomberg.com/research/stocks/private/snapsh ot.asp?privcapid=27242372, checked on 1/19/2019.

[3] Böttcher, D. (2015). Marc O'Polo. Nie wieder soll es heißen: Haben wir nicht. brandeins.de. Available online at https://www.brandeins.de/magazine/brand-eins-wirtschafts magazin/2015/handel/nie-wieder-soll-es-heissen-haben-wir -nicht, checked on 11/3/2018.

[4] Coughlan, A., Anderson, E., Stern, L.W., \& El-Ansary, A.I. (2001). Marketing Channels, Pearson/ Prentice Hall, Upper Saddle River, NJ.

[5] Fang, Y., Qureshi, I., Sun, H., McCole, P., Ramsey, E., \& Lim, K. H. (2014). Trust, satisfaction, and online repurchase intention: The moderating role of perceived effectiveness of e-commerce institutional mechanisms. MIS Quarterly, 38(2), 407-427.

[6] Jobstmann, S. (2015). Fallbeispiel: Marc O’Polo kombiniert alle Kanäle dank Innomos. e-commerce-magazin. Available online athttps://www.e-commerce-magazin.de/fachartikel/f allbeispiel-marc-opolo-kombiniert-alle-kanaele-dank-inno mos, checked on 11/1/2018.

[7] Lettow, R. (2015). Marc O’Polo: For Members. Fabeau. Fashionnetwork.com. Available online at https://de.fashion network.com/news/Marc-O-Polo-For-Members,777622.ht ml\#.W91V45MzY2x, updated on $3 / 31 / 2015$, checked on $11 / 3 / 2018$

[8] Marc O’Polo Einzelhandels GmbH (2018a). Company. Facts \& Figures. Available online at https://company.marco-polo.com/en/company/facts-figures, updated on 5/1/2018, checked on 11/1/2018.

[9] Marc O’Polo Einzelhandels GmbH (2018b). History. Available online at https://company.marc-o-polo.com/en/co mpany/history, checked on 10/31/2018.

[10] Marc O’Polo Einzelhandels GmbH (2018c). Service \& Contact. Available online at https://de.marc-o-polo.com/ser vice-und-kontakt/newsletter.html, checked on 11/3/2018.

[11] Smith, G. (2015). Driving Brand Loyalty in a Multichannel World. multichannelmerchant.com. Available online at https://multichannelmerchant.com/blog/driving-brand-loyal ty-multichannel-world/, updated on 2/18/2015, checked on $11 / 8 / 2018$

[12] Weber, S., \& Rossi, M. (2015). How to Execute An Effective Multichannel Customer Loyalty Program. retailtouchpoints.tumblr.com. Available online at https://retailtouchpoints.tumblr.com/post/111571985887/ho w-to-execute-an-effective-multichannel-customer, checked on $11 / 6 / 2018$.

[13] Yumurtacı Hüseyinoğlu, I. Ö., Galipoğlu, E., \& Kotzab, H. (2017). Social, local and mobile commerce practices in omni-channel retailing: insights from Germany and Turkey. International Journal of Retail \& Distribution Management, 45(7/8), 711-729. 